\title{
Spare the Rod? Ideology, Experience, and Attitudes Toward Child Discipline Among Presbyterian Clergy
}

\author{
Margaret L. Vaaler • Christopher G. Ellison •
}

Karissa D. Horton • John P. Marcum

Published online: 18 July 2008

(C) Springer Science + Business Media, LLC 2008

Dr. Jack Marcum is the Coordinator of Research Services at the General Assembly Council of the Presbyterian Church (U.S.A.).

The online version of the original article can be found at http://dx.doi.org/10.1007/s11089-008-0129-y

M. L. Vaaler $(\bowtie) \cdot$ C. G. Ellison $\cdot$ K. D. Horton

University of Texas at Austin, 1 University Station A1700, Austin, TX 78712, USA

e-mail: mvaaler@prc.utexas.edu 